\title{
PREVALENCE OF ORTHOPAEDIC INJURIES DUE TO ROAD SIDE ACCIDENTS IN EAST MADHYA PRADESH REGION OF CENTRAL INDIA
}

\author{
Amit Kumar Chaurasia ${ }^{1}$, Prateek Ahlawat ${ }^{2}$ \\ ${ }^{1}$ Associate Professor, Department of Orthopaedics, S.S. Medical College \& SGM Hospital, Rewa. \\ ${ }^{2}$ Post Graduate Student, Department of Orthopaedics, S.S. Medical College \& SGM Hospital, Rewa.
}

\section{ABSTRACT}

\section{AIM}

This study carried out in Department of Orthopaedics, S.S. Medical College and Sanjay Gandhi Memorial Hospital, Rewa, MP to study the orthopaedic injury caused by road traffic accidents and factors responsible for these injuries.

\section{BACKGROUND}

Road traffic accidents are one of the major causes of death in developed as well as developing countries. India accounts for about $10 \%$ of road accident fatalities worldwide and more deaths are recorded due to traffic crashes than due to cardiovascular diseases or neoplasms.

\section{METHODS}

The present study was carried out on the patients injured due to road traffic injuries admitted in orthopaedic ward of Shyam Shah Medical College and associated Sanjay Gandhi Memorial Hospital, Rewa (MP), during the one-year period from $1^{\text {st }}$ October 2014 to $30^{\text {th }}$ September 2015. The collected data was classified and coded as per the guidelines laid down under the WHO/CDC Injury Surveillance System and ICECI.

\section{RESULTS}

This study showed that the majority of crash victims were males in the age group 20-44 years accounting for huge economic losses for their families and the country at large. Motorized two-wheeler accounted for $46.78 \%$ of the accidents. Out of total accident victims, $45 \%$ were drivers and riders; $49.47 \%$ of accidents occurred between $4 \mathrm{pm}$ to 12 pm. Most drivers/riders mentioned had not taken safety measure (Helmet/seat belt) during accident. Fractures (87.97\%) were the most common nature of injuries and lower limb was more commonly involved than the upper limb.

\section{CONCLUSION}

Road traffic accidents are preventable. Strict traffic laws and penalties have to be imposed to curb this ever growing menace.

\section{KEYWORDS}

Orthopaedic Injuries, Road Side Accidents, CDC-WHO Injury Surveillance Guidelines.

HOW TO CITE THIS ARTICLE: Chaurasia AK, Ahlawat P. Prevalence of orthopaedic injuries due to road side accidents in East Madhya Pradesh region of Central India. J. Evolution Med. Dent. Sci. 2016;5(21):1080-1085, DOI: 10.14260/jemds/2016/250

\section{INTRODUCTION}

Road transport is a critical structure for economic development of a country. It influences the pace, structure and pattern of development. Surge in population and motorization in the country along with expansion of road network contributes to the number of road accidents, injuries and fatalities.(1)

Over 1.2 million people die each year on the world's roads with millions more sustaining serious injuries and living with long-term adverse health consequences. Globally, road traffic crashes are a leading cause of death among young people and the main cause of death among those aged 15-29 years.(2) Road traffic injuries are currently estimated to be the ninth leading cause of death across all age groups globally and are predicted to become the seventh leading cause of death by 2030.

Financial or Other, Competing Interest: None.

Submission 14-02-2016, Peer Review 27-02-2016,

Acceptance 01-03-2016, Published 11-03-2016.

Corresponding Author:

Dr. Amit Kumar Chaurasia,

Chaurasia Hospital, Jail Road,

Rewa-486001,

Madhya Pradesh.

E-mail:amit140975@yahoo.com

DOI: $10.14260 /$ jemds $/ 2016 / 250$
As well as being a public health problem, road traffic injuries are a development issue: low- and middle income countries lose approximately 3\% of GDP as a result of road traffic crashes.(2) During the year 2013 there were 4,86,476 road accidents, which resulted in deaths of 1,37,572 people and injury of $4,94,893$ persons in India. These numbers translate into 1 road accident every minute and 1 road accident death every 4 minutes.(1)

\section{OBJECTIVES}

- To know the incidence injuries due to road traffic accidents, falls, other unnatural causalities of trauma in different age groups.

- To know the causes of the above and to identify some environmental factors like time and month of the accident.

- To analyse the types of injury sustained by the victim with emphasis on orthopaedic injuries using WHO/CDC Injury Surveillance System Guidelines and ICECI.

- $\quad$ To suggest preventive measures.

- To become conversant with the WHO/CDC Injury Surveillance System Guidelines and ICECI to study its applicability and efficacy and practical utility. 


\section{MATERIALS AND METHODS}

The present study was carried out on the patients injured due to road traffic injuries admitted in orthopaedic ward of Shyam Shah Medical College and associated Sanjay Gandhi Memorial Hospital, Rewa (MP), during the one-year period from $1^{\text {st }}$ October 2014 to $30^{\text {th }}$ September 2015.

\section{Ethical Clearance}

The study is started only after obtaining Ethical Clearance from the Institutional Ethical Committee.

\section{Study Setting}

Department of Orthopaedics, Shyam Shah Medical College and associated Sanjay Gandhi Memorial Hospital, Rewa (MP).

\section{Sample and Sample Size}

740 patients injured due to road traffic accidents admitted in orthopaedic ward of Shyam Shah Medical College and associated Sanjay Gandhi Memorial Hospital, Rewa (MP), during the one-year period from $1^{\text {st }}$ October 2014 to $30^{\text {th }}$ September 2015 were included in the study.

\section{Statistical Analysis}

Age, sex, type of vehicle involved, common site of injuries, type of injuries and other factors are noted in the Proforma. The data is then entered in the computer database, which will be analysed.

\section{Methodology}

As soon as a person injured in a road traffic accident arrives to the casualty, initial management of his/her general condition will be done. Once the person is stabilized, the patient is informed in detail about the study and then the information sheet which contains all the information regarding the study will be issued to the patient or relatives. After the consent of the patient or relative, the injured person's name, age, sex and two Identification marks are recorded. History about the accident regarding, time, month, type of vehicle, road user status of the victim will be recorded. A meticulous clinical examination of injuries will be done to note the type, site, size and other features of the injuries. All the findings will be recorded in the Proforma. The collected data was classified and coded as per the guidelines laid down under the WHO/CDC Injury Surveillance System and ICECI.

\section{OBSERVATIONS AND RESULTS}

\section{Core Minimum Data}

\section{Age and Sex Wise Distribution}

Age and sex distribution clearly reflects the dominance of males over females in general $(82.02 \%$ male and $17.98 \%$ female) and victims of age group of 25-44 years (40.54\%) were maximally affected. We deduced the data and found that out of 740 cases of RTAs $57.7 \%$ were of this age group ( $50.67 \%$ males) high incidence of trauma on roadside.

\begin{tabular}{|c|c|c|c|c|c|c|}
\hline \multirow{2}{*}{$\begin{array}{c}\text { Age Group } \\
\text { (In years) }\end{array}$} & $\begin{array}{c}\text { Total } \\
\text { No. }\end{array}$ & $\%$ & Male & $\%$ & Female & $\%$ \\
\hline Less than 5 & 13 & 1.75 & 8 & 1.08 & 5 & 0.63 \\
\hline $5-14$ & 55 & 7.43 & 37 & 5 & 18 & 2.43 \\
\hline $15-19$ & 72 & 9.72 & 62 & 8.37 & 10 & 1.35 \\
\hline $20-24$ & 127 & 17.16 & 118 & 15.94 & 9 & 1.21 \\
\hline $25-44$ & 300 & 40.54 & 257 & 34.73 & 43 & 5.81 \\
\hline $45-64$ & 125 & 16.9 & 92 & 12.43 & 33 & 4.47 \\
\hline$>64$ & 48 & 6.48 & 33 & 4.45 & 15 & 2.03 \\
\hline Total & $\mathbf{7 4 0}$ & $\mathbf{1 0 0}$ & $\mathbf{6 0 7}$ & $\mathbf{8 2 . 0 2}$ & $\mathbf{1 3 3}$ & $\mathbf{1 7 . 9 8}$ \\
\hline
\end{tabular}

\section{Activity of the Patient When Accident Occur}

About $67.02 \%$ of the victims were travelling as a part of some work, whereas $18.1 \%$ of the victims were travelling as a part of their routine or unrelated to some work.

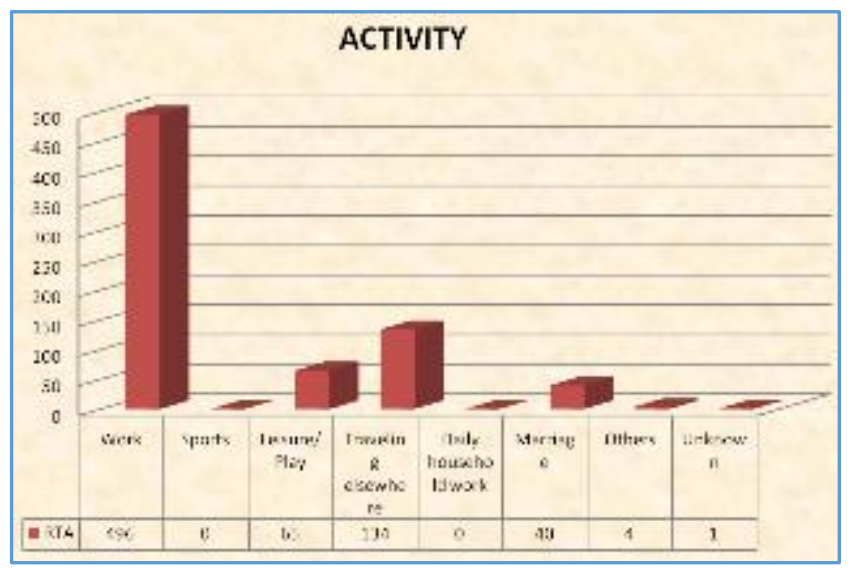

Nature of Injury Sustained after the Accident

$87.97 \%$ of the patients were having fractures of the bones and about $5.13 \%$ of the victims were having dislocations.

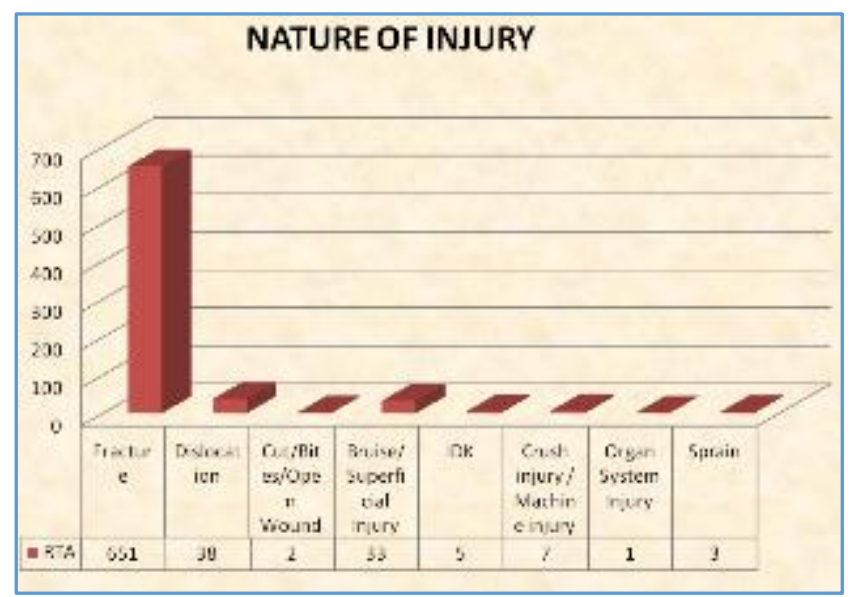

\section{CORE OPTIONAL DATA}

\section{Distribution of Accident Cases by Time of Occurrence}

Majority of road traffic accidents happened in the evening from 4 pm to 7:59 pm (29.2\%) followed by early night hours of $8 \mathrm{pm}$ to $11: 59 \mathrm{pm}(20.27 \%)$. Lowest number of accidents was recorded during night-time from 12:00 to 3 am (2.43\%).

\begin{tabular}{|c|c|c|}
\hline Time & No. of Patients & Percentage (\%) \\
\hline $00: 00-03: 59 \mathrm{am}$ & 18 & 2.43 \\
\hline $04: 00-07: 59 \mathrm{am}$ & 45 & 6.08 \\
\hline $08: 00-11: 59 \mathrm{am}$ & 126 & 17 \\
\hline $12: 00-03: 59 \mathrm{pm}$ & 185 & 25 \\
\hline $04: 00-07: 59 \mathrm{pm}$ & 216 & 29.2 \\
\hline $08: 00-11: 59 \mathrm{pm}$ & 150 & 20.27 \\
\hline Total & $\mathbf{7 4 0}$ & $\mathbf{1 0 0}$ \\
\hline \multicolumn{3}{|c|}{ Table 2: Distribution of accident } \\
cases by time of occurrence \\
\hline
\end{tabular}

\section{Month Wise Distribution of RTA}

Highest number of cases were reported during the months of May (11.4\%). Lowest number of cases was found to be reported during the month of February and September $(6.5 \%$ each). 


\section{Residence of the Patient}

Most of the patients belonged to Rewa.

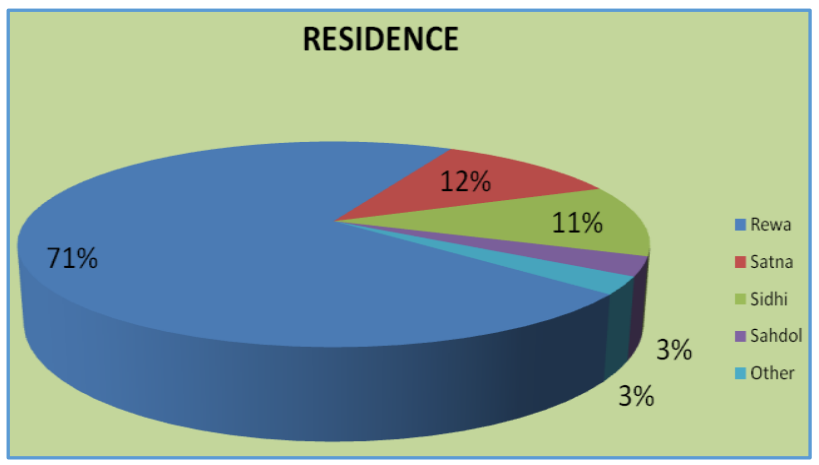

\section{Severity of the Injury Sustained}

$76.91 \%$ of the patients were having moderate severity, whereas those having severe injuries $(14.81 \%)$ required intensive management.

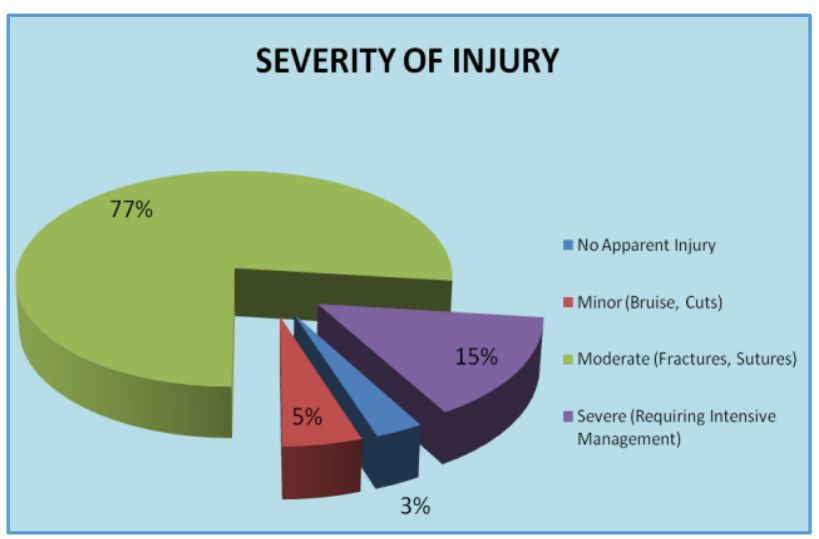

Disposition of the Patient from Hospital

$83 \%$ of the patients were treated and discharged. There was a mortality rate of $0.41 \%$.

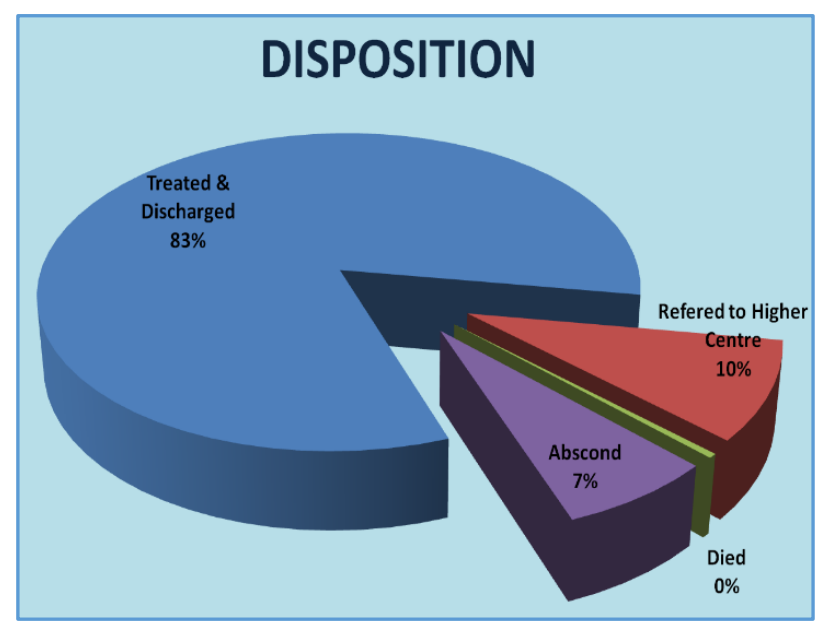

\section{SUPPLEMENTARY MINIMUM DATA}

Mode of Transport and Type of Vehicle Involved in

\section{Accident}

Total of vulnerable road users (pedestrians, cyclists and motorcyclists) were $79 \%$. Two-wheelers were the most common vehicle (46.78\%) followed by pedestrian $(20.64 \%)$. MUV (Jeep, Marshal, Commander) and Auto were found responsible for $11.39 \%$ of accidents.

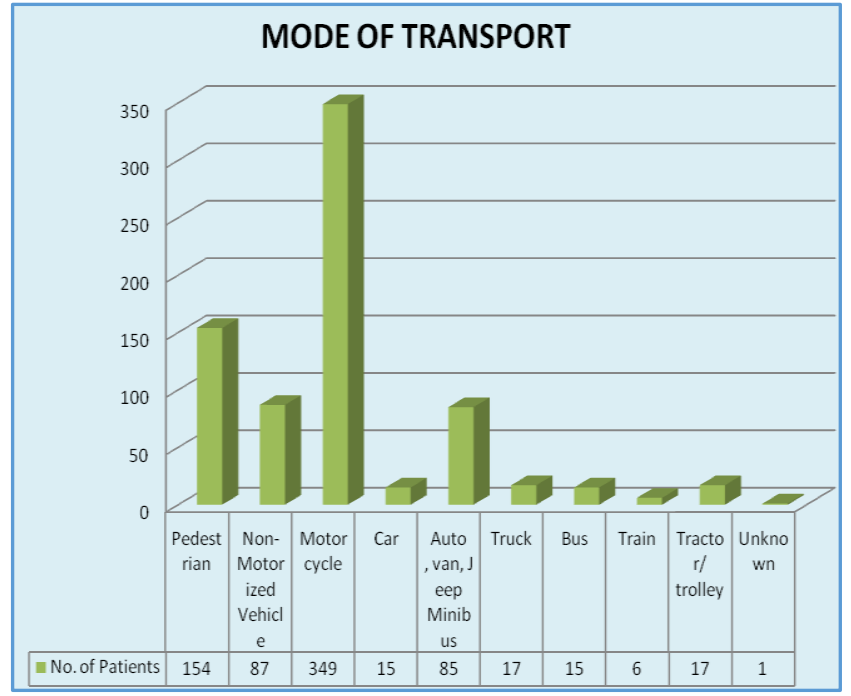

\section{Road User Status of the Victim}

Drivers were involved in significant number of cases (45\%). Passengers were victims in $33.87 \%$.

\begin{tabular}{|c|c|c|}
\hline & No. of Patients & Percentage (\%) \\
\hline Pedestrian & 155 & 21 \\
\hline Driver/Operator & 340 & 45 \\
\hline Passenger & 250 & 33.87 \\
\hline Unknown & 1 & 0.13 \\
\hline Total & $\mathbf{7 4 6}$ & $\mathbf{1 0 0}$ \\
\hline \multicolumn{2}{|c|}{ Table 3: Road user's status of the victim } \\
\hline
\end{tabular}

\section{SUPPLEMENTARY OPTIONAL DATA}

\section{Counterpart to which the Vehicle Struck}

Counterpart in $66.62 \%$ of the cases was another motorized vehicle. About $29.06 \%$ of the cases were as a result of noncollision (Fall due to slipping and overturning).

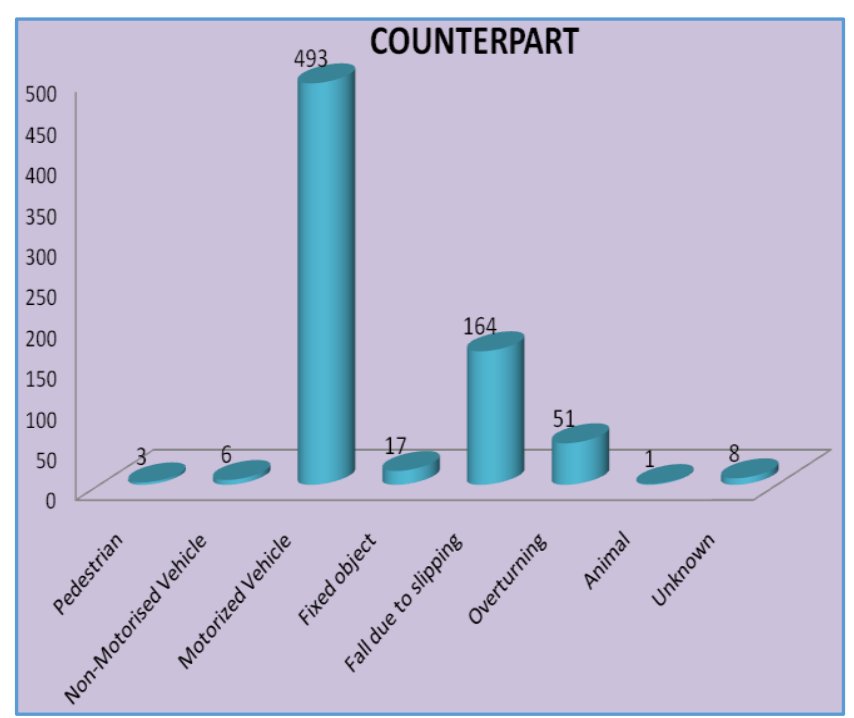

Type of the Collision Sustained During Accident While analyzing various modes of RTAs, side on collisions were found to be more common (41.41\%) followed by head on collision $(19.05 \%)$. 


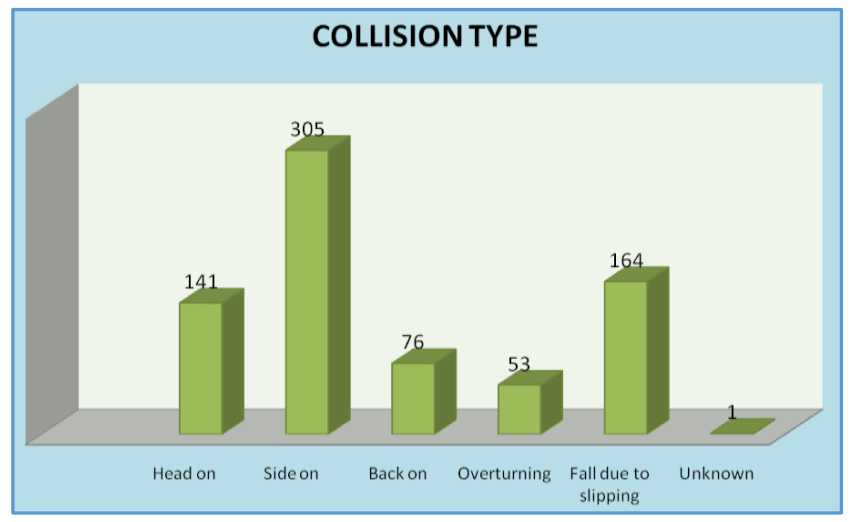

Alcohol Usage by the Victim at Time of Accident

$9.4 \%$ of the patients were under the effect of alcohol at the time of accident.

\section{Helmet Usage by the Victim at Time of Accident}

None of the two wheeler occupants were wearing helmet while they met with the accident in our study.

\section{Pattern of Injuries in RTA}

- Lower limb was more commonly involved (72.56\%) than upper limb (26.62\%).

- $\quad$ Fracture tibia and fibula (36.35\%) (Most common site mid $1 / 3^{\text {rd }}$ in $16.89 \%$ ).

- $\quad$ Fracture femur (28.37\%) (Most common site mid $1 / 3^{\text {rd }}$ in $12 \%$ ).

- $\quad$ Femur and tibia, both were involved in $2.83 \%$ patients.

- In upper limb arm was involved in $11.5 \%$ (Most common being the lower $1 / 3 \mathrm{rd}$ shaft and lower end of humerus) and forearm in $8 \%$ (Most common being fracture both bone forearm) of the cases.

- Among children below 14 years, (68 patients) fracture femur was more common (24 patients, $35.29 \%$ ) than fracture tibia fibula (19 patients, $28 \%$ ).

- Small bones of hand and foot were fractured in $2.4 \%$.

- Two bones were simultaneously fractured in $9 \%$ of patients. Three or more bone were fractured in $1 \%$ of patients, as the road traffic accidents were high energy trauma.

- $1 \%$ of patients have spinal injuries with $0.4 \%$ having neurological deficit.

- Dislocation of hip joint was the most common (2.7\%) followed by shoulder joint (2\%) and elbow joint ( $0.8 \%)$.

- Crush injury was found in $1 \%$ of cases.

\section{Compound Fractures in RTAs}

- Compound fractures were found in $21.9 \%$ patients.

- Most common was compound fracture tibia and fibula (65.43\% of all compound fractures) and $39.4 \%$ of tibia fractures were compound. Tibia, mid $1 / 3$ tibia fibula was most common (50\%), but only $42.4 \%$ of mid $1 / 3$ were compound and $50 \%$ of lower $1 / 3$ tibia fracture were compound.

- Compound fracture femur constituted $13.6 \%$ of total compound fractures and only $10.4 \%$ of femur fractures were compound.

- Upper limb compound fracture constituted $12.3 \%$ of compound fracture; $20 \%$ of forearm fractures and $9.4 \%$ of arm fractures were compound.

\section{DISCUSSION}

RTAs are a major public health problem in all over the world. In developing countries like India, exposure to potential road traffic injuries have increased largely because of expansion in road network, rapid motorization, urbanization, poor road condition, lack of safety feature in vehicles, crowded roads, poor road maintenance and lack of prevailing law enforcement by the police.(3)

In Rewa like other cities in India, roads are congested and encroached mostly by two wheelers, bicyclists and pedestrian. There are very few traffic signals and zebra crossings in the city. There is insufficient public transport facilities and people mostly rely on own vehicle (Mostly bicycle, bike), auto rickshaw or pedestrian for transportation. In the present study, the highest no. of RTA victims were males as compared to females and were mostly in 3rd and 4 th decade of their life. Similar results were found from studies from South India, Maharashtra, Nepal, Hapur, Ghaziabad, Assam, etc. $(4,5,6,7,8,9,10)$ Other studies by Dalbir et al.(11), Shrivastava SR et al.(12), Pranab Jyoti Bhuyan et al.(13), and Manisha Ruikar.(14) showed the same results. The probable causes of male preponderance in RTA can be that in Indian setup outdoor activities are mostly carried by male counterpart.

The probable causes of RTA in youth group can be rash, speedy driving, negligence as well as inexperience among this group. This results in great loss to family members as well the country, because this is the most productive age group and expenditure incurred in the treatment of these victims is not less.

Most of the victims (67.02\%) were travelling as a part of some work followed by people travelling unrelated to some work. We could not find any study mentioning the activity of the person at the time of accident.

Most common nature of injury, the patients (87.97\%) were having fractures of the bones and about $5.13 \%$ of the victims were having dislocations. Other studies conducted by Kirti Jaiswal.(15) et al. and Seth Sharad et al.(16) reported similar results. While Suresh Katageri, Ram Babu Sharma et al.(17) and Ruma Dutta et al.(18) reported soft tissue injuries as most common injuries. This is in contrast to other studies as the study included only the admitted patients in ward.

It was shown in our study that peak time of accident was between $4 \mathrm{pm}$ to $8 \mathrm{pm}$ followed by 8 am to $12 \mathrm{pm}$. Study done by Ranjana Singh et al.(8) peak time for accident was between 6 am to $6 \mathrm{pm}$. Similar results were obtained by many other researchers.(11,12,13,4) The data is comparable and may be attributed to bad light condition, fast and reckless driving increased traffic load and frustration of tired drivers. It was attributed to the travelling frequency and vehicle use in this region, which is maximum during this time.

Maximum number of accidents occurred in the month of May. About 38.6\% occurred in the month of April, May, June, July. This can mainly be attributed to the season of marriage in May and June, during which the number of overloaded vehicles and increased number of drunken drivers. The data is comparable in few studies.(14) and disparity among the others.(13,19) may be attributed to the lifestyle, different topographical and social trends in different areas.

Most (76.91\%) of the patients were having moderate severity including fracture requiring skilled or operative management, whereas those having severe injuries (14.81\%) 
required intensive management. Majority (83\%) of the patients were treated and discharged. There was a mortality rate of $0.41 \%$. We did not find any studies regarding severity of injuries.

Total of vulnerable road users (pedestrians, cyclists and motorcyclists) was about $4 / 5$ th. Two-wheelers were the most common vehicle $(46.78 \%)$ due to less control and high speed, followed by pedestrian (20.64\%) and MUV (Jeep, Marshall, Commanders) and Auto were found responsible for $11.39 \%$ of accidents. Their higher incidence (pedestrians of our study) could be attributed to low socio-economic status of the public hence forced to be either pedestrians or to use jeeps or autos, lack of segregation of traffic, bad roads on which they are driving, also driven recklessly keeping at stake all the rules and regulations of traffic. Data was comparable to different studies.(11,12,13,14)

Drivers were involved in higher number of cases (45\%), which could be attributed to dominance of two-wheelers involved in the occurrence of the accident. Passengers were victims in $33.87 \%$. Among bike accidents rider sustained more injuries, which is comparable to other studies (Shamim Haider et al.(20) reported out of total accident victims, 62 (48.1\%) were drivers and riders, Supriya Keisham, Salam Bitam Singh et al.(21)), which can be due to single occupant of vehicle in many cases and also the driver being more prone of getting hit by other vehicle like in front on collision.

Counterpart in one of the cases was another motorized vehicle followed by significant number of the cases were as result of non-collision (fall due to slipping and overturning). While analysing various modes of RTAs, side on collisions were found to be more common followed by head on collision. The teenagers driving the vehicles at uncontrolled speed, bad roads with poor layouts and sharp turns explain higher incidences of RTAs.

One reason that we could conclude for various types of RTAs was defective road laying and population establishment of our country. It means that our national highways pass through many villages and townships and roads become narrow at these places in addition to increased traffic, especially pedestrians. Traffic moving at a high speed on highways suddenly lands up moving through the villages/townships where schools, bazaars, etc. are at full swing especially in the evening hours, giving a fertile land for the human attributes to RTAs to grow and flourish still further.

In this study, it was found that $9.4 \%$ of the patients were under the effect of alcohol at time of accident. It is well documented that alcohol impairs driving ability, which leads to accidents.

Similar findings were obtained in studies done by Patil SS.(5) where $29.5 \%$ of the drivers involved had consumed alcohol. In the study done by Jha $\mathrm{N}$ et al.(4) in South India, $15 \%$ of the drivers had consumed alcohol. Higher percentage of drivers had consumed alcohol in studies done by many researchers. $(13,22,23)$ The reason could be easy accessibility of the vehicle and inadequate enforcement of existing law. The numbers are very low compared to other studies, which can be due to false history given by people and the exact status of patient cannot be determined as lot of patients presenting late being referred from other hospitals.
None of the two wheeler occupants were wearing helmet while they met with an accident in our study. Non usage of helmet can be attributed to poor traffic law enforcement and also wide disregard of people to traffic rules and their own safety because of more poor, uneducated and rural population. Similar results of less use of helmet were obtained in studies done by other researchers. $(18,21,22,23)$

Lower limb was more commonly involved than upper limb, which can mainly be attributed to bumper injuries and traffic injuries being high energy trauma. Fracture tibia and fibula (Most common site mid $1 / 3^{\text {rd }}$ ) as in most of the bumper injuries leg was involved and also it lies freely by the side of bike and vulnerable of being hit in side on collision. It also contributed to more of compound injuries in leg than any other part. Similar results were obtained in other studies. $(7,13,22)$ We could not find any literature correlating the modes and mechanism of trauma to pattern of injuries till yet.

\section{CONCLUSIONS}

The majority of road traffic accident victims were male comprising of $82 \%$ and female comprised of only $18 \%$. The age group commonly involved in accidents in both the sexes is 20-44 years. Accidents are more during the month of May. Accidents were more in the evening hours. Two wheelers are the most common vehicles involving in the accident; $9.4 \%$ of the victims were found to have used alcohol. Fracture is the commonest nature of injury produced.

\section{REFERENCES}

1. Report of Road accident in India 2013, Ministry of Road Transport and Highway. http://www.morth.nic.in assessed on 2015.

2. WHO- Global status report on road safety 2015.

3. Heidi Worley, Road traffic accidents increase dramatically worldwide population reference bureau, 2006. www.prb.org/Publications/Articles/2006/.aspx Assessed on 2015.

4. Jha N, Srinivasa DK, Roy G, et al. Injury pattern among road traffic accident cases: a study from south India. Indian Journal of Community Medicine 2003;28(2):8590.

5. Patil SS, Kakade RV, Durgawale PM, et al. Pattern of road traffic injuries. Indian Journal of Community Medicine 2008;33(1):56-57.

6. Mishra, Sinha ND, Sukhla SK, et al. Epidemiological study of RTA from Nepal. Indian Journal of Community Medicine 2010;35(1):115-121.

7. Singh R, Singh HK, Gupta SC, et al. Pattern, severity and circumstances of injuries sustained in road traffic accidents: a tertiary care hospital-based study. Indian J Community Med 2014;39(1):30-4.

8. Ranjana Singh, Bhatnagar $M$, Singh $H K$, et al. An epidemiological study of victims of road traffic accidents. Indian J Prev Soc Med 2011;42(1):28-33.

9. Bhuyan PJ, Ahmed F. Road traffic accident: an emerging public health problem in Assam. Indian J Community Med 2013;38(2):100-4.

10. Maj SM Pathak, Col AK Jindal, Brig AK Verma, et al. An epidemiological study of road traffic accident cases admitted in a tertiary care hospital. Medical journal armed forces India 2014;70(1):32-35. 
11. Dalbir Singh, Satinder PS, Kumaran M, et al. Epidemiology of road traffic accident deaths in children in Chandigarh zone of north west India. Egyptian Journal of Forensic Sciences 2015.

12. Shrivastava SR, Pandian P, Shrivastava PS. Pre-hospital care among victims of road traffic accident in a rural area of Tamil Nadu: a cross-sectional descriptive study. Frost a J Neurosci Rural Pract 2014;5(1):S33-8.

13. Pranab Jyoti Bhuyan, Faruquddin Ahmed. Road traffic accident: an emerging public health problem in Assam. Indian J Community Med 2013;38(2):100-104.

14. Manisha Ruikar. National statistics of road traffic accidents in India. 2015;IP 49.14.249.108. www.jotr.in .

15. Kirti Jaiswal, Sandip K, Santhosh KS, et al. Injury pattern of road traffic accident cases in a rural hospital of central Uttar Pradesh. International Journal of Medical Science and Public Health 2015;4(10):13471350.

16. Seth Sharad, Keshav A, Parnnika A, et al. A retrospective study of road traffi $\mathrm{c}$ accidents-injurycharacteristics, management and outcome at Rohilkhand. International Journal of Medical Science Research and Practice 2015;2(2):72-76.

17. Suresh Katageri, Ram Babu Sharma, Govindaraju HC, et al. Pattern of injuries in road traffic accidents at Chitradurga Karnataka: an autopsy based atudy. J Indian Acad Forensic Med. 2015;37(2):173-175. ISSN 0971-0973
18. Ruma Dutta, Dinesh Raja, Lawrence D, et al. Profile of RTA cases attending a tertiary health care centre in Kanchipuram district of Tamil Nadu. International Journal of Recent Trends in Science And Technology 2015;14(1):1-3. ISSN 2277-2812 E-ISSN 2249-8109.

19. Maduakonam DE, Miriam DU, Arthur N. Retrospections on road traffic injuries as a social burden: the role of public health education initiatives in a developing country. Niger J Med 2015;24(2):169-74.

20. Shamim Haider, Shalini $S$, Mithilesh $K$, et al. An epidemiological study of road traffic accidents in Rajendra institute of medical sciences (RIMS) Ranchi. International Journal of Interdisciplinary and Multidisciplinary Studies 2015;3(1):18-24.

21. Supriya Keisham, Salam Bitam Singh, Kamie R, et al. A study of fatal internal injuries without significant external injuries in road traffic accidents in imphal from 2009-2014. J Indian Acad Forensic Med 2015;37(1):1618. ISSN 0971-0973.

22. Amita Aggarwal, Sukhpal K, Mandeep SD, et al. Sociodemographic profile of road traffic accident victims admitted at emergency surgical OPD of a tertiary care hospital. ResearchGate 2012. DOI:10.5005/jp-journals-10028-1005.

23. Bayan P, Bhawalkar JS, Jadhav SL, et al. Profile of nonfatal injuries due to road traffic accidents from a industrial town in India. Int J Crit Illn Inj Sci 2013;3(1):8-11. 